\title{
Pesquisa de Salmonella spp. e microrganismos indicadores em carcaças de frango e água de tanques de pré-resfriamento em abatedouro de aves
}

\section{Research of Salmonella spp. and indicators microorganisms in poultry carcasses and chilling tanks water in poultry slaughterhouse}

\author{
Melissa Lopes ${ }^{1 *}$; Juliana Arena Galhardo²; Juçara Tinasi de Oliveira ${ }^{3}$; \\ Ronaldo Tamaninit; Samuel Fabre Sanches ${ }^{5}$; Ernst Eckehardt Muller ${ }^{6}$
}

\section{Resumo}

O objetivo desse trabalho foi pesquisar Salmonella spp. e microrganismos indicadores (coliformes totais-CT, coliformes termotolerantes-CTT, aeróbios mesófilos-AM e microrganismos psicrotróficosMP) em carcaças de frango e água dos tanques de pré-resfriamento em um frigorífico do norte do Paraná. Foram analisadas 120 carcaças de frango (60 antes do pré-chiller e 60 após a saída do chiller) e 120 amostras de água (60 pré-chiller e 60 do chiller), totalizando 20 coletas. Para as análises utilizaram-se a metodologia recomendada pela legislação brasileira e sistema Petrfilm ${ }^{\mathrm{TM}} \mathrm{AC}$. Salmonella spp. foi isolada em uma carcaça antes do pré-chiller e outra após a saída do chiller, ambas identificadas como Salmonella O8, 20: $\mathrm{z}_{4}, \mathrm{z}_{23}$. Nas amostras de água foram isolados e identificados seis sorovares no pré-chiller, cinco Salmonella $\mathrm{O} 8,20 ; \mathrm{z}_{4}, \mathrm{z}_{23}$ e um $S$. Tennessee. As médias de CT nas carcaças antes do pré-chiller e após a saída do chiller e na água destes tanques foram 3,74 NMP/g, 3,10 NMP/g e 4,00 NMP/100mL/2,81 NMP/ $100 \mathrm{~mL}$ respectivamente; CTT 3,65 NMP/g /3,00 NMP/g e 3,81 NMP/100mL/2,73 NMP/100mL; AM 6,40 $\mathrm{UFC} / \mathrm{g} / 5,60 \mathrm{UFC} / \mathrm{g}$ e 4,40 UFC/mL / 4,13 UFC/mL; MP 4,21 UFC/g e de 3,66 UFC/g. Nas carcaças de frango antes do pré-chiller e após o chiller e na água do pré-chiller e chiller não foi observada diferença significativa $(p>0,05)$ nos índices de contaminação com relação aos microrganismos indicadores estudados. Pelos resultados obtidos pode-se concluir que no frigorífico estudado não houve redução da contaminação bacteriana das carcaças durante a passagem pelos tanques.

Palavras-chave: Salmonella spp, coliformes totais, coliformes termotolerantes, mesófilos, psicrotróficos, frango

\begin{abstract}
The purpose of this work was to research the Salmonella spp. and indicators microorganisms (total coliforms-CT, thermotolerant coliforms-CTT, mesophlic aerobes-AM and psychotrophic microorganisms) in poultry carcasses and chilling tanks water in a poultry slaughterhouse in north of Paraná state. Had been analyzed 120 poultry carcasses ( 60 before the entrance in the chilling tank and 60 after the exit of the chilling tank) and 120 water samples (60 from pre-chiller tank and 60 from chiller tank), totalizing 20 collections. For the analyses was used the brazilian legislation and Petrifilm ${ }^{\mathrm{TM}} \mathrm{AC}$. Salmonella spp. was isolated in one poultry carcass before the entrance in the chilling tank and other after the exit of the
\end{abstract}

\footnotetext{
1 Mestrado em Ciência Animal, Sanidade Animal / UEL, Londrina. E-mail: melissa_lopes@ hotmail.com.

2 Mestrado em Ciência Animal, Sanidade Animal / UEL, Londrina.

3 Aluna de Graduação / Medicina Veterinária / UEL, Londrina.

4 Mestrado em Ciência Animal, Sanidade Animal / UEL, Londrina.

5 Departamento de Estatística / CCE / UEL, Londrina.

6 Departamento de Medicina Veterinária Preventiva / CCA / UEL, Londrina.

* Autor para correspondência
} 
chilling tank, both identified as Salmonella $\mathrm{O} 8,20 ; \mathrm{z}_{4} \mathrm{z}_{23}$. In the water samples was recognized six serovars in pre-chiller tank, five as Salmonella $\mathrm{O} 8,20 ; \mathrm{z}_{4} \mathrm{z}_{23}$ and one $S$. Tennessee. The means of TC on carcasses before the entrance and after the exit of the tanks and in the water samples from pre-chiller tank and in chiller were $3,74 \mathrm{MPN} / \mathrm{g} / 3,10 \mathrm{MPN} / \mathrm{g}$ and 4,00 MPN/100mL/2,81 MPN/100mL respectively; the mean of TCC was 3,65 MPN/g /3,00 MPN/g and 3,81 MPN/100mL /2,73 MPN/100mL; the mean of MA was 6,40 CFU/g / $5,60 \mathrm{CFU} / \mathrm{g}$ and $4,40 \mathrm{CFU} / \mathrm{mL}$ e $4,13 \mathrm{CFU} / \mathrm{mL}$; the mean of MP was $4,21 \mathrm{CFU} / \mathrm{g} / 3,66 \mathrm{CFU} / \mathrm{g}$ and . It was not observed any significant difference $(\mathrm{p}>0,05)$ in contamination index neither in poultry carcasses nor in tank water samples. It is possible to conclude that chilling tanks were not able to remove the microorganisms from the carcasses and could contribute to cross-contamination due to elevate water contamination.

Key words: Salmonella spp, total coliforms, thermotolerant coliforms, mesophilic aerobes, psychrotrophic, poultry

\section{Introdução}

O comércio internacional de carne e derivados de frangos foi influenciado negativamente a partir do ano de 2003, principalmente, pela ocorrência da Influenza Aviária e desvalorização do dólar. Apesar das dificuldades, a avicultura tem apresentado crescimento anual. Atualmente, o Brasil é o segundo produtor e o primeiro exportador mundial de carne de frango, segundo dados da União Brasileira de Avicultura (UNIÃO BRASILEIRA DE AVICULTURA, 2006). O consumo interno tem apresentado tendência favorável ao crescimento devido aos atributos de carne saudável, baixo preço e aumento da comercialização de derivados prontos para o consumo (TALAMINI; MARTINS; NOVAES, 2005).

De acordo com Almeida e Silva (1992), a contaminação das carcaças de aves envolve adesão das bactérias por um filme liquido sobre a pele. McMeekin e Thomas (1978) e Firstenberg-Eden, Notermans e Schothorst (1978), verificaram que as bactérias ficavam retidas na pele de frangos após a imersão das carcaças em suspensões bacterianas e esta retenção apresentava relação linear com as contagens bacterianas da suspensão.

Grande parte desses microrganismos não são patogênicos, porém bactérias como Salmonella spp., Campylobacter jejuni, Listeria monocytogenes, Escherichia. coli enteropatôgenica $e$ Staphylococcus aureus podem estar presentes, representando um risco potencial à saúde do consumidor (SILVA, 1998; JAMES; PRUCHA; BREWER, 1993). Algumas espécies de Salmonella spp. são capazes de aderir firmemente às fibras de colágeno da superfície externa da pele do frango; essa adesão não depende somente da presença de fímbrias, podendo ocorrer apenas pelo contato da célula microbiana com a pele do frango na presença de água (THOMAS; McMEEKIN; PATTERSON, 1986).

Dados epidemiológicos sobre toxinfecções alimentares vem mostrando um aumento significativo de salmoneloses nos últimos trinta anos, até mesmo em países com excelentes serviços de saúde. As carnes de frango e as vermelhas são consideradas como as principais vias de transmissão de salmonelose, e a contaminação da ração animal tem sido reconhecida como via primária de transmissão para os animais, originando grande número de portadores de Salmonella spp. clinicamente sadios, potenciais disseminadores desse microrganismo, mesmo durante o processamento das carcaças (SILVA, 1998).

A segurança e qualidade dos alimentos como a carne in natura pode ser estimada pela contagem de microrganismos indicadores como microrganismos aeróbios mesófilos (AM), coliformes totais (CT), E.coli (EC) e microrganismos psicrotróficos (PC). A contagem de AM fornece uma estimativa da população microbiana total e elevadas contagens usualmente estão relacionadas à baixa qualidade e reduzida vida de prateleira do alimento (JAY, 2000; GILL, 1998). As contagens de CT e EC podem estimar falhas na higiene e indicar contaminação de origem fecal, sendo que elevadas contagens destes grupos de microrganismos podem estar relacionadas a níveis significativos de enteropatógenos, como a Salmonella spp. (JAY, 2000; 
EISEL; LINTON; MURIANA, 1997; GILL; McGINNIS; BADONI, 1996).

Neste estudo objetivou-se pesquisar Salmonella spp. e microrganismos indicadores em carcaças de frango e água de tanques de pré-resfriamento.

\section{Material e Métodos}

\section{Coleta das amostras}

No período de Março a Setembro de 2005, com intervalo mínimo de uma semana foram efetuadas 20 coletas de amostras de carcaças de frango e água em um frigorífico localizado na região norte do Estado do Paraná com abate diário de aproximadamente 30 mil frangos. Em cada coleta foram amostradas três carcaças de frango $(\mathrm{n}=60)$, diretamente da nória, antes de cair no pré-chiller e três carcaças na nória de gotejamento ( $n=60)$, após a saída do chiller. As amostras de carcaças foram acondicionadas em sacos estéreis.

Paralelamente as coletas das carcaças foram obtidas 60 amostras de água do pré-chiller e 60 do chiller. Cada amostra de água foi constituída de 300 $\mathrm{mL}$ coletada em vidros de cor âmbar esterilizados contendo $0,2 \mathrm{~mL}$ de tiossulfato de sódio a $10 \%$ (BRASIL, 2004), totalizando 120 amostras de água.

As amostras foram mantidas em caixa isotérmica com gelo reciclável, por no máximo seis horas até o processamento nos Laboratórios de Microbiologia e Doenças Infecciosas e Zoonoses e Saúde Pública da Universidade Estadual de Londrina.

Aferição do fluxo de água, temperatura $e$ cloração dos tanques de resfriamento

O fluxo de água (L/carcaça) foi calculado a partir do volume registrado nos hidrômetros. Para a avaliação do fluxo foi considerado o gelo normalmente adicionado nos tanques (em média 840L para o pré-chiller e 1520L para o chiller).

A temperatura dos tanques e a cloração do chiller foram aferidos no momento de coleta das amostras de frango e água empregando termômetro manual
(Quimis ${ }^{\circledR}$, Diadema, São Paulo, Brasil) e kit de cloro a base de ortotuluidina (Hanna Instruments Brasil ${ }^{\circledR}$ ,São Paulo, São Paulo, Brasil).

\section{Preparo das amostras}

De cada carcaça foram removidos assepticamente e pesados $25 \mathrm{~g}$ de pele e músculos das regiões do pescoço, asas e cloaca e acondicionados em sacos de polietileno estéreis de $\left(\mathrm{Nasco}^{\circledR}\right.$, Califórnia, EUA) contendo $225 \mathrm{~mL}$ de água peptonada tamponada a $1 \%$ e estéril (Biobrás ${ }^{\circledR}$, Montes Claros, Minas Gerais, Brasil). Estas amostras foram homogeneizadas em aparelho stomacher (ITR Ltda ${ }^{\circledR}$, Esteio, Rio Grande do Sul, Brasil) por três minutos sendo este conteúdo equivalente à diluição $10^{-1}$. As diluições subseqüentes foram realizadas em solução salina $0,85 \%$, estéril. As carcaças de frango foram submetidas à pesquisa de Salmonella spp., CT, CTT, MA e MP.

Para a análise da água foram homogeneizados e transferidos $100 \mathrm{~mL}$ da amostra para um frasco estéril contendo $50 \mathrm{~mL}$ de água peptonada a $1 \%$ para realizar a pesquisa de Salmonella spp. Foram realizadas as diluições de $10^{-2}, 10^{-3}, 10^{-4}, 10^{-5}$ e $10^{-6}$ em tampão fosfato com cloreto de magnésio e efetuadas as inoculações nos meios de cultura para a pesquisa de CT, CTT e contagem de MP.

\section{Análises microbiológicas}

Para a pesquisa de Salmonella spp. as amostras homogeneizadas de carcaças $(25 \mathrm{~g}+225 \mathrm{~mL}$ de água peptonada) e água $(10 \mathrm{~mL}$ das amostra $+50 \mathrm{~mL}$ de água peptonada) foram incubadas a $35^{\circ} \mathrm{C}$ por $18-24$ horas, segundo a Portaria $\mathrm{n}^{\circ} 8$ do Ministério da Agricultura, Pecuária e Abastecimento (BRASIL, 1995). O enriquecimento seletivo foi efetuado em caldo Tetrationato (TT) (Difco ${ }^{\circledR}$, Kansas, EUA), preparado conforme as instruções do fabricante, inoculando alíquotas de $1 \mathrm{~mL}$ das amostras homogeneizadas em $9 \mathrm{~mL}$ do caldo com incubação a $43^{\circ} \mathrm{C}$ por 24 horas, em banho-maria circular. Após o enriquecimento seletivo, alíquotas do meio TT foram estriadas em placas contendo ágar verde brilhante 
vermelho de fenol lactose sacarose (BPLS) (Biobrás ${ }^{\circledR}$, Montes Claros, Minas Gerais, Brasil) e Hektoen (Acumedia ${ }^{\circledR}$, Canadá, EUA) preparados conforme as instruções do fabricante. Ambas foram incubadas a $35^{\circ} \mathrm{C}$ por 24 horas em estufa bacteriológica (Fanem Ltda ${ }^{\circledR}$, São Paulo, Brasil).

Do ágar BPLS e Hecktoen foram selecionadas colônias características (incolores ou de cor rosada e colônias com centro negro e com halo transparente, respectivamente) e semeadas nos meios ágar tríplice açúcar ferro (TSI), lisina ferro (LIA), ágar uréia e feninalalina (FA). As cepas com características bioquímicas de Salmonella spp. foram semeadas no ágar Rambach (Merck ${ }^{\circledR}$, Darmstadt, Germany). Colônias com tonalidade rósea ou avermelhada foram confirmadas através da prova de soroaglutinação rápida com anti-soro somático e flagelar polivalente (Probac do Brasil ${ }^{\circledR}$, São Paulo, São Paulo, Brasil). Todas as cepas que aglutinaram com o anti-soro polivalente foram enviadas ao Laboratório de Enterobactérias do Instituto Oswaldo Cruz (FIOCRUZ), Rio de Janeiro, Brasil, para sorotipagem.

Para a determinação do Número Mais Provável (NMP) de CT em carcaças de frango foi utilizada a técnica de tubos múltiplos numa série de nove tubos e três diluições $\left(10^{-2}, 10^{-3}\right.$ e $\left.10^{-4}\right)$ contendo caldo lactosado bile verde brilhante 2\% (CLBVB) $\left(\right.$ Merck $^{\circledR}$, Darmstadt, Germany). Dos tubos positivos, incubados a $37^{\circ} \mathrm{C}$ por $24-48$ horas foram transferidos $30 \mu \mathrm{L}$ para caldo EC (Vetec ${ }^{\circledR}$, Rio de Janeiro, Rio de Janeiro, Brasil) e para caldo triptona (CT)(Synth ${ }^{\circledR}$, Diadema, São Paulo, Brasil) para determinação do NMP de CTT, que foram incubados a $44,5^{\circ} \mathrm{C} \mathrm{em}$ banho-maria por 24-48 horas. Os tubos foram considerados positivos no EC e CT quando apresentaram turvação do meio com produção de gás e anel de coloração vermelha (teste do indol) (BRASIL, 1993).

Para a contagem de CT em amostras de água utilizou-se a técnica de tubos múltiplos em cinco séries de cinco tubos contendo caldo lactosado (Biobrás ${ }^{\circledR}$, Montes, Claros, Minas Gerais, Brasil), nas diluições $10^{0}, 10^{-1}, 10^{-2}, 10^{-3}$ e $10^{-4}$. A partir dos tubos com turvação e produção de gás após 48 horas de incubação a $37^{\circ} \mathrm{C}$ foram inoculadas alíquotas de 0,3 $\mathrm{mL}$ para tubos contendo CLBVB, incubados em estufa a $37^{\circ} \mathrm{C}$ por até 48 horas, e alíquotas de $0,3 \mathrm{~mL}$ para tubos contendo caldo $\mathrm{EC}$ incubados a $44,5^{\circ} \mathrm{C}$ por 24 horas em banho-maria. Os tubos foram considerados positivos nos caldos CLBVB e EC quando apresentaram turvação do meio com produção de gás (BRASIL, 2004).

Para a enumeração de AM das carcaças de frango, $1 \mathrm{~mL}$ das diluições $10^{-4}$ e $10^{-6}$ foram semeadas em placas Petrifilm ${ }^{\mathrm{TM}} \mathrm{C}\left(3 \mathrm{M}^{\circledast}\right.$, Sumaré, São Paulo, Brasil), com incubação a $35^{\circ} \mathrm{C}$ por 48 horas.

MP foram enumerados semeando $0,1 \mathrm{~mL}$ das diluições $10^{-1}$ a $10^{-5}$ (carcaças de frango) e $10^{-2}$ a $10^{-}$ ${ }^{4}$ (água do chiller) por superfície e em duplicata em placas contendo ágar padrão de contagem, com incubação a $7^{\circ} \mathrm{C}$ por 10 dias (BRASIL, 1993).

Todas as contagens obtidas foram convertidas em logaritmo decimal $\left(\log _{10}\right)$ e expressas em Log NMP/ g para CT e CTT nas carcaças, Log UFC/g para pesquisa de AM e MP em carcaças, Log NMP/ $100 \mathrm{~mL}$ para CT e CTT na água e $\log \mathrm{UFC} / \mathrm{mL}$ para MP na água.

\section{Análise estatística}

Para a análise estatística foi aplicada a ANOVA e o teste de Tukey para duas amostras, num nível de significância de $5 \%(\mathrm{p}<0,05)$. Os dados foram analisados através do programa Prism 4.03.

\section{Resultados e Discussão}

A legislação brasileira em vigência (BRASIL, 1998) determina que a temperatura máxima da água do pré-chiller seja de $16^{\circ} \mathrm{C}$ e do chiller de até $4^{\circ} \mathrm{C}$, e que o nível de cloro livre na água deve ser no máximo de 5 ppm não havendo limite mínimo estabelecido. O fluxo de água por carcaça com peso entre 2,5 e 5,0 Kg é de no mínimo 1,5L no pré-chiller e $1,0 \mathrm{~L}$ no chiller. 
No frigorífico estudado, a temperatura média da água do chiller e pré-chiller (Tabela 1) estava de acordo com os parâmetros estabelecidos pela legislação brasileira, sendo a média da água do pré- chiller de $13,42^{\circ} \mathrm{C}$ a do chiller de $3,52^{\circ} \mathrm{C}$. Entretanto, em alguns dias de coleta as médias de temperatura do chiller estiveram acima do parâmetro estabelecido pela legislação.

Tabela 1. Valores de temperatura $\left(\mathrm{T}^{\circ} \mathrm{C}\right)$, fluxo de água por carcaça (Fluxo) e cloro livre (Cloro) aferidos na água dos tanques de pré-resfriamento de um frigorífico avícola de pequeno porte localizado no norte do Estado do Paraná, Brasil.

\begin{tabular}{|c|c|c|c|c|c|}
\hline \multirow[b]{2}{*}{ N/Coleta } & \multicolumn{2}{|c|}{ Pré-chiller } & \multicolumn{3}{|c|}{ Chiller } \\
\hline & $\mathrm{T}^{\circ} \mathrm{C}$ & $\begin{array}{c}\text { FLUXO } \\
\text { (L/carcaça) }\end{array}$ & $\mathrm{T}^{\circ} \mathrm{C}$ & $\begin{array}{c}\text { FLUXO } \\
\text { (L/carcaça) }\end{array}$ & CLORO (ppm) \\
\hline 1 & 14,33 & 1,20 & 3,67 & 0,74 & 0,5 \\
\hline 2 & 11,33 & 0,82 & 3,67 & 0,66 & 0,5 \\
\hline 3 & 14,00 & 0,90 & 3,67 & 0,83 & 0,5 \\
\hline 4 & 13,33 & 1,11 & 4,00 & 1,02 & 0,5 \\
\hline 5 & 14,00 & 1,03 & 5,00 & 0,98 & 0,5 \\
\hline 6 & 14,67 & 1,07 & 3,33 & 1,01 & 0,5 \\
\hline 7 & 11,67 & 1,00 & 3,00 & 1,03 & 0,5 \\
\hline 8 & 15,00 & 1,61 & 7,00 & 0,74 & 0,7 \\
\hline 9 & 12,00 & 1,17 & 2,67 & 0,84 & 1,0 \\
\hline 10 & 15,67 & 1,14 & 4,00 & 0,80 & 4,0 \\
\hline 11 & 13,00 & 1,24 & 1,33 & 0,89 & 4,0 \\
\hline 12 & 13,33 & 1,18 & 2,00 & 0,91 & 5,0 \\
\hline 13 & 12,33 & 1,17 & 2,67 & 0,89 & 1,0 \\
\hline 14 & 14,00 & 1,16 & 3,33 & 0,88 & 4,0 \\
\hline 15 & 14,00 & 1,05 & 4,67 & 0,90 & 2,0 \\
\hline 16 & 12,00 & 1,06 & 3,67 & 0,91 & 4,0 \\
\hline 17 & 14,00 & 1,15 & 2,33 & 0,91 & 4,0 \\
\hline 18 & 13,00 & 1,19 & 4,00 & 0,90 & 4,0 \\
\hline 19 & 13,33 & 1,12 & 3,67 & 0,95 & 8,0 \\
\hline 20 & 13,33 & 0,84 & 2,67 & 0,77 & 6,0 \\
\hline MÉDIA & 13,42 & 1,11 & 3,52 & 0,88 & 2,56 \\
\hline
\end{tabular}

Os níveis de cloro residual na água do chiller aumentaram gradativamente ao longo das 20 coletas, sendo o mínimo observado de $0,5 \mathrm{ppm}$, durante as primeiras sete coletas e o máximo de 6 e 8 ppm nas últimas duas semanas, respectivamente, sendo a média de 2,6 ppm (Tabela 1). Embora a maioria dos resultados verificados apresentaram-se dentro do que determina a legislação, o sistema manual de cloração e a inexistência de um protocolo utilizado pela Empresa, pode ter prejudicado o processo de cloração.

No período da realização da pesquisa os valores do fluxo de água (Tabela 1) foram inferiores aos exigidos pela legislação, sendo as médias aferidas para o pré-chiller de $1,11 \mathrm{~L}$ por carcaça e de $0,88 \mathrm{~L}$ para o chiller. 
Das 120 carcaças pesquisadas, duas foram positivas para Salmonella spp, sendo que uma carcaça foi coletada antes do pré-chiller e a outra após o chiller. O sorovar identificado nas duas carcaças foi Salmonella O8, 20: $\mathrm{z}_{4}, \mathrm{z}_{23}$ (Tabela 2).

Tabela 2. Freqüência de isolamento de Salmonella spp. e sorovares identificados em amostras de carcaças de frangos antes e após o processo de resfriamento em um frigorífico avícola de pequeno porte localizado no norte do Estado do Paraná, Brasil.

\begin{tabular}{clcc}
\hline $\mathrm{N}^{\circ} /$ Coleta & Ponto de amostragem & Isolamento Salmonella / $(\%)$ & Sorovares \\
\hline 5 & Após o Chiller & $1 / 6(16,6 \%)$ & $S .08,20: \mathrm{z}_{4}, \mathrm{z}_{23}$ \\
11 & Antes do pré-chiller & $1 / 6(16,6 \%)$ & $S .08,20: \mathrm{z}_{4}, \mathrm{z}_{23}$ \\
\hline
\end{tabular}

A Agência Nacional de Vigilância Sanitária (ANVISA-RDC $\mathrm{n}^{\circ}$. 12/2001) aprovou o Regulamento Técnico sobre Padrões Microbiológicos para Alimentos, e somente estabeleceu que Salmonella spp. deve estar ausente em $25 \mathrm{~g}$ de carnes resfriadas, ou congeladas, "in natura", de bovinos, suínos e outros mamíferos (carcaças inteiras ou fracionadas, quartos ou cortes), carnes moídas; miúdos de bovinos, suínos e outros mamíferos, ovos e derivados (BRASIL, 2001). Observa-se que a resolução exclui a carne de frango, mas a ANVISA através da RDC n. ${ }^{\circ}$ 39/2002 (BRASIL, 2002) aprovou o Regulamento técnico para Instruções de Uso, Preparo e Conservação na Rotulagem de Carnes de Aves e seus Miúdos Crus, Resfriados ou Congelados com instruções mínimas obrigatórias para que auxiliem o consumidor no controle do risco associado ao consumo destes alimentos nos quais a Salmonella spp. pode estar presente.

Resultados diferentes dos observados no presente trabalho foram verificados por Almeida e Silva (1992) que observaram uma maior ocorrência de Salmonella spp. após o resfriamento das carcaças de frango em um abatedouro com evisceração mecânica (4/12), o qual apresentava temperatura de $21^{\circ} \mathrm{C}$ e $6^{\circ} \mathrm{C}$ e zero de cloro residual nos dois tanques de resfriamento e um outro com evisceração manual (2/12), o qual apresentava $21^{\circ} \mathrm{C}$ e $2^{\circ} \mathrm{C}$ e cloro residual acima de $5 \mathrm{ppm}$ nos dois tanques de resfriamento. Os autores discutem a possibilidade da água dos tanques de préresfriamento, ter participação na contaminação cruzada das carcaças por salmonelas.
Lillard (1990) relatou que uma pesquisa realizada pelo Serviço de Inspeção nos Estados Unidos ("Food Safety and Inspection Service") monstrou que 5\% das aves que chegavam ao abatedouro estavam contaminadas por Salmonella spp., e após a etapa final do processamento a contaminação aumentou para $36 \%$ nas carcaças dos frangos.

Dickel et al. (2005) analisaram 60 carcaças coletadas antes e depois da passagem pelo chiller em um abatedouro de tecnologia semi-automatizada com abate diário de 20 mil aves e um de tecnologia totalmente automatizada e abate diário de $380 \mathrm{mil}$ aves no Rio Grande do Sul. Os autores não encontraram Salmonella spp. no primeiro abatedouro, mas no segundo verificaram uma elevada freqüência de salmonela $(70 \%$, antes do chiller e $20 \%$ depois do chiller). Pode-se inferir que as altas velocidades nas linhas de abate, equipamentos desregulados, desuniformidade no tamanho das aves, temperaturas inadequadas no pré-chiller e chiller e cloração deficiente, possibilitaram a contaminação cruzada com enterobactérias, entre elas, as salmonelas paratificas.

A contaminação cruzada observada no presente trabalho, também pode ser justificada pelo fato de o frigorífico estudado apresentar tecnologia automatizada, temperaturas inadequadas no préchiller e chiller e cloração deficiente.

$\mathrm{O}$ uso de apenas um meio de enriquecimento seletivo neste trabalho pode ter influenciado na 
recuperação de um número baixo de Salmonella spp. Os meios de enriquecimento seletivo recomendados pela "Association of Official Analytical Chemist" (AOAC) e pela "Food and Drug Administration" (FDA) são os caldos selenito cistina (SC) e tetrationato (TT), enquanto que, a "International Organization for Standardization" (ISO) recomenda TT e Rappaport-Vassiliadis (RV) (RIPABELL et al., 1997). No Brasil, a legislação (BRASIL, 1995) sugere apenas o uso de TT ou SC. Vários estudos já foram realizados comparando a eficiência dos meios líquidos de enriquecimento seletivo. Ramalho, Lima e Silva (2000) obtiveram melhores resultados com a combinação entre TT e RV, sendo que das 30 amostras de carcaças de frango analisadas, 13 $(43,3 \%)$ foram positivas para Salmonella spp. Resultados semelhantes foram encontrados por
Nogueira e Franco (1996) que detectou 46 amostras positivas em 100 analisadas.

Poucos são os trabalhos encontrados na literatura que analisaram a água dos tanques de préresfriamento atuando na contaminação cruzada de Salmonella spp. em carcaças de frangos.

Das 120 amostras de água analisadas neste trabalho, seis $(5,0 \%)$ foram positivas para Salmonella spp. Todas as amostras foram coletadas da água do pré-chiller. Dos seis sorovares, cinco foram identificados como Salmonella O8, 20: $\mathrm{z}_{4}, \mathrm{z}_{23}$ e um como $S$. Tennessee (Tabela 3). Salmonella O8, 20: $\mathrm{z}_{4}, \mathrm{z}_{23}$ pertence ao grupo das salmonelas paratíficas que são representadas por, aproximadamente, 1500 sorovares podendo ser encontrados em aves e mamíferos clinicamente saudáveis, sendo de grande relevância para a saúde pública.

Tabela 3. Freqüência de isolamento de Salmonella spp. e sorovares identificados em amostras de água do pré-chiller em um frigorífico avícola de pequeno porte localizado no norte do Estado do Paraná, Brasil.

\begin{tabular}{ccc}
\hline No/ Coleta & Amostras positivas/n (\%) & Sorovares \\
\hline 8 & $1 / 6(16,6 \%)$ & S. Tennessee \\
& $2 / 6(33,3 \%)$ & Salmonella $\mathrm{O} 8,20: \mathrm{z}_{4}, \mathrm{z}_{23}$ \\
9 & $1 / 6(16,6 \%)$ & Salmonella $\mathrm{O} 8,20: \mathrm{z}_{4}, \mathrm{z}_{23}$ \\
11 & $2 / 6(33,3 \%)$ & Salmonella. $\mathrm{O} 8,20: \mathrm{z}_{4}, \mathrm{Z}_{23}$ \\
\hline
\end{tabular}

Lillard (1990) isolou Salmonella spp em 52,8\% de um total de 54 amostras de água analisadas do tanque de resfriamento, e observou que o tanque é um local que favorece a contaminação cruzada.

O sorovar Tennessee já esteve presente entre os mais frequientes isolados em episódios de infecção alimentar em humanos no Brasil (CAUDURO; MEZZANI; DIAS, 1986). Pesquisas mostram que esse sorovar tem sido isolado de leite em pó destinado ao consumo de crianças (CENTER FOR DISEASES CONTROL, 1993), matérias-primas e ração para aves (HOFER; SILVA FILHO; REIS, 1997), em fezes e linfonodos mesentéricos de suínos abatidos em frigoríficos do Rio Grande do Sul (BESSA;
COSTA; CARDOSO, 2004) e em abatedouros de aves (DICKEL et al., 2005). S. Tennessee pode ser introduzida em uma granja através da compra de aves, água, ração ou equipamentos contaminados ou pelo homem.

As médias logarítmicas de CT nas carcaças de frango variaram de 3,24 NMP/g a 4,04 NMP/g no pré-chiller. A variação para os frangos que saíram do chiller foi de 1,85 NMP/g a 3,69 NMP/g. Não houve diferença significativa ( $p>0,05)$ entre as médias logarítmicas do número mais provável de $\mathrm{CT}$ em relação a entrada e a saída dos tanques, em um mesmo dia de coleta (Tabela 4). 
Tabela 4. Médias logarítmicas, desvio padrão e contagens mínimas e máximas de coliformes totais, coliformes termotolerantes $\left(\log _{10} \mathrm{NMP} / \mathrm{g}\right)$, psicrotróficos e aeróbios mesófilos $\left(\log _{10} \mathrm{UFC} / \mathrm{g}\right)$ das amostras de carcaças frango coletadas antes do pré-chiller e após a passagem pelo chiller das 20 coletas em um frigorífico avícola de pequeno porte localizado no norte do Estado do Paraná, Brasil.

\begin{tabular}{lcccc}
\hline \multirow{2}{*}{$\begin{array}{c}\text { Padrão } \\
\text { Microbiológico }\end{array}$} & \multicolumn{2}{c}{ Antes do Pré-chiller $(\mathrm{n}=60)$} & \multicolumn{2}{c}{ Após o Chiller (n=60) } \\
\cline { 2 - 5 } & $\begin{array}{c}\text { Intervalo de } \\
\text { contagem }\end{array}$ & $\begin{array}{c}\text { Média de } \\
\text { contagem }\end{array}$ & $\begin{array}{c}\text { Intervalo de } \\
\text { contagem }\end{array}$ & $\begin{array}{c}\text { Média de } \\
\text { contagem }\end{array}$ \\
\hline CT & $2,3-4,40$ & 3,74 & $0,0-4,04$ & 3,10 \\
CTT & $2,3-4,04$ & 3,65 & $0,0-4,04$ & 3,00 \\
MP & $2,0-6,63$ & 4,21 & $2,0-5,74$ & 3,66 \\
AM & $4,0-8,41$ & 6,4 & $4,0-8,05$ & 5,60 \\
\hline
\end{tabular}

CT: Coliformes Totais

CTT: Coliformes Termotolerantes

MP: Microrganismos Psicrotróficos

AM: Aeróbios Mesófilos

Para CTT a legislação (BRASIL, 2001) estabelece um limite máximo de $10^{4} \mathrm{UFC} / \mathrm{g}$ em carnes resfriadas ou congeladas de aves. As médias logarítmicas de CTT nas carcaças de frango variaram de 3,24 NMP/g a 3,91 NMP/g no pré-chiller e de 1,73 $\mathrm{NMP} / \mathrm{g}$ a 3,69 NMP/g no chiller, variações abaixo do limite máximo estabelecido pela legislação brasileira. Não houve diferença significativa $(p>0,05)$ entre as médias logarítmicas (Tabela 4).

De acordo com a literatura, níveis de contaminação por $\mathrm{AM}$ de $10^{2}$ a $10^{5} \mathrm{UFC} / \mathrm{cm}^{2} \mathrm{em}$ carnes podem indicar condições higiênicas adequadas no abate e contagens acima de $10^{5}$ podem significar condições inadequadas (GILL, 1998). Contaminações de carne em torno de $10^{6} \mathrm{UFC} / \mathrm{cm}^{2}$ podem indicar início do processo de deterioração com produção de odor desagradável e comprometimento da vida de prateleira. Com contagens iguais ou superiores a $10^{7}$ $\mathrm{UFC} / \mathrm{cm}^{2}$ limosidade já pode ser evidenciada (GILL, 1998; FRANCO; LANDGRAF, 2002). Apesar da legislação atual não estabelecer limites para AM e MP, as contagens obtidas sugerem deficiência durante o processamento das carcaças.

Na Tabela 4 constam os resultados das contagens de AM e MP, respectivamente. As médias logarítmicas mais elevadas obtidas antes da entrada das carcaças no pré-chiller foram de 7,42 NMP/g para AM e 5,73 NMP/g para MP. Após o chiller as médias logarítmicas mais elevadas foram de 6,62 $\mathrm{NMP} / \mathrm{g}$ a 5,32 NMP/g, para AM e MP, respectivamente. Não houve diferença significativa ( $>0,05)$ entre as médias logarítmicas do número mais provável de CT do pré-chiller e chiller. As médias logarítmicas variaram de 2,69 NMP/100mL a 5,20 NMP/100mL no pré-chiller e de 0,84 NMP/ $100 \mathrm{~mL}$ a $5,04 \mathrm{NMP} / 100 \mathrm{~mL}$ no chiller. Nas amostras de água do pré-chiller e chiller também não apresentaram diferença significativa $(p>0,05)$ com relação às médias de CTT que variaram de 2,41 log $\mathrm{NMP} / 100 \mathrm{~mL}$ a $5,20 \mathrm{NMP} / 100 \mathrm{~mL}$ no pré-chiller e de $0,84 \mathrm{NMP} / 100 \mathrm{~mL}$ a 5,04 NMP/100mL no chiller. As médias logarítmicas das contagens de MP não apresentaram diferença significativa $(\mathrm{p}>0,05)$ na água do pré-chiller e chiller (Tabela 5).

Os resultados deste trabalho mostram que, no frigorífico estudado, a passagem das carcaças de frangos pelos tanques de pré-resfriamento não diminuiu de maneira significativa a contaminação das carcaças. Trabalhos publicados por Ritter e Bergman (2003), Thomson et al. (1975) e Thomson, Cox e Bailey (1976) também demonstraram que os tanques de resfriamento não foram eficazes na redução da contaminação bacteriana em carcaças. Porém, Smith, Cason e Berrang (2005), Soares, Rezende e Srebernich (2005), Reiber et al. (1990), Campbell et al. (1983) e Surkiewicz et al. (1969), afirmaram que os tanques foram eficazes na higienização das carcaças. 
Tabela 5. Médias logarítmicas, desvio padrão e contagens mínimas e máximas de coliformes totais, coliformes termotolerantes $\left(\log _{10} \mathrm{NMP} / \mathrm{g}\right)$, psicrotróficos e aeróbios mesófilos $\left(\log _{10} \mathrm{UFC} / \mathrm{g}\right)$ da água do pré-chiller e do chiller das 20 coletas em um frigorífico avícola de pequeno porte localizado no norte do Estado do Paraná, Brasil.

\begin{tabular}{lcccc}
\hline \multirow{2}{*}{$\begin{array}{c}\text { Padrão } \\
\text { Microbiológico }\end{array}$} & \multicolumn{2}{c}{ Antes do Pré-chiller $(\mathrm{n}=60)$} & \multicolumn{2}{c}{ Após o Chiller $(\mathrm{n}=60)$} \\
\cline { 2 - 5 } & $\begin{array}{c}\text { Intervalo de } \\
\text { contagem }\end{array}$ & $\begin{array}{c}\text { Média de } \\
\text { contagem }\end{array}$ & $\begin{array}{c}\text { Intervalo de } \\
\text { contagem }\end{array}$ & $\begin{array}{c}\text { Média de } \\
\text { contagem }\end{array}$ \\
\hline CT & $0,30-5,38$ & 4,00 & $0,30-5,20$ & 2,81 \\
CTT & $2,23-5,20$ & 3,81 & $0,30-5,20$ & 2,73 \\
MP & $2,30-6,60$ & 4,40 & $2,00-7,28$ & 4,13 \\
\hline
\end{tabular}

CT: Coliformes Totais

CTT: Coliformes Termotolerantes

MP: Microrganismos Psicrotróficos

Vários fatores podem influenciar nas contagens de microrganismos em carcaças imersas nos tanques de pré-resfriamento, como o fluxo de água (L/ carcaça), temperatura, cloração, grau de contaminação das carcaças antes do pré-chiller e higienização dos equipamentos. Neste trabalho o fluxo insuficiente de água, a contaminação das carcaças antes da passagem pelo pré-chiller e a higienização inadequada dos equipamentos podem ter influenciado a ineficácia dos tanques de préresfriamento na diminuição da contaminação das carcaças. Houston (1985) e Mead (1974) verificaram que a eficácia da higienização das carcaças no chiller depende, essencialmente, da quantidade de água usada. Volume e fluxo inadequados de água podem propiciar um acúmulo de microrganismos no chiller aumentando os níveis de contaminação das carcaças.

Neste trabalho observou-se que não houve diferença significativa nas médias das contagens de microrganismos nos frangos, antes e após a passagem pelos tanques, assim como na água do pré-chiller e chiller. Isto poderia ser explicado pela contaminação elevada das carcaças antes do pré-resfriamento, higienização inadequada dos equipamentos, fluxo de água insuficiente e temperaturas da água dos tanques de pré-resfriamento acima das preconizadas pela legislação em algumas aferições.

Os resultados obtidos nesta pesquisa indicaram que no frigorífico pesquisado: os tanques de pré- resfriamento não foram eficazes em reduzir a carga microbiana das carcaças, pois não foi verificada diferença significativa entre as médias de microrganismos indicadores nas carcaças antes e após o resfriamento; a presença de Salmonella spp. em duas (2/120) carcaças de frango, sendo uma após o resfriamento, e em seis (5/120) amostras de água do pré-chiller representam risco à saúde pública; os sorovares encontrados nas carcaças e água $(S$. Tennessee e Salmonella O8, 20: $\mathrm{z}_{4}, \mathrm{z}_{23}$ ) pertencem ao grupo das salmonelas paratíficas.

Estes resultados reforçam a necessidade de continuar a busca de procedimentos de controle que visem a redução dos níveis de contaminação de carcaças de frango por Salmonella, e conseqüentemente reduzir o risco potencial de transferência destes microrganismos para humanos através do consumo de alimentos preparados a base de produtos de origem animal contaminados. Tais procedimentos incluem necessariamente a implantação de programas de análise de risco e controle de pontos críticos, envolvendo desde a criação do animal até o preparo do alimento pelo consumidor, passando especialmente pelo processamento do produto na planta industrial. Isto permitirá uma melhoria na qualidade microbiológica do produto final. 


\section{Referências}

ALMEIDA, P. F.; SILVA, E. N. Estudos sobre a disseminação bacteriana em carcaças de frangos de abatedouros industriais. Arquivo Brasileiro de Medicina Veterinária e Zootecnia, Belo Horizonte, v.44, n.2, p.105120, 1992.

BESSA, M. C.; COSTA, M.; CARDOSO, M. Prevalência de Salmonella em suínos abatidos em frigoríficos do Rio Grande do Sul. Pesquisa Veterinária Brasileira, Rio de Janeiro, v.24, n.2, p.80-84, 2004.

BRASIL. Fundação Nacional de Saúde. Manual prático de análise de água. Brasília: Fundação Nacional de Saúde, 2004.

BRASIL. Ministério da Agricultura, Abastecimento e Reforma Agrária. Portaria n.101, de 17.de agosto de 1993. Método de análise microbiológica para alimentos. 19911992. Brasília: Ministério da Agricultura, do Abastecimento e da Reforma Agrária, 1993.

BRASIL. Ministério da Agricultura, Pecuária e Abastecimento. Divisão de Produtos de Origem Animal. Portaria n.210 de 10 de novembro de 1998. Regulamento técnico de inspeção tecnológica e higiênico-sanitária de carne de aves. Brasília: M.A.A., 1998.

BRASIL. Ministério da Agricultura, Pecuária e Abastecimento. Portaria n.8, de 23 de Janeiro de 1995. Método analítico de carcaças de aves e pesquisa de Salmonella. Brasilia: Ministério da Agricultura, 1995.

BRASIL. Ministério da Saúde. Agência Nacional de Vigilância Sanitária. Resolução RDC n.39 de 8 de fevereiro de 2002. Regulamento técnico para instruções de uso, preparo e conservação na rotulagem de carne de aves e seus miúdos crus, resfriados ou congelados. Brasilia: Ministério da Saúde, 2002.

BRASIL. Ministério da Saúde. Agência Nacional de Vigilância Sanitária. Resolução RDC n.12 de 2 de janeiro de 2001. Regulamento técnico sobre os padrões microbiológicos para alimentos. Disponível em: <http:// e-legis.anvisa.gov.br/leisref/public/ showAct.php?id=144>. Acesso em: 22 out. 2005.

CAMPBELL, D. F.; JOHNSTON, R. W.; CAMPBELL, G. S.; McCLAIN, D.; MACALUSO, J. F. The microbiology of raw, eviscerated chickens: a ten yearscomparison. Poultry Science, Champaign, v.68, n.5, p.656-662, 1983.

CAUDURO, P. F.; MEZZANI, A.; DIAS, C. A. G. Isolamento de Salmonella tennessee em fezes humanas no Rio Grande do Sul. Revista de Microbiologia, São Paulo, v.17, n.2, p.113-119, 1986.
CENTER FOR DISEASES CONTROL. Salmonella serotype Tennessee in powdered milk products and infant formula. Canadá, 1993. Disponível em: <http://www.cdc.gov/mmwr/ preview/mmwrhtml/00021081.htm>. Acesso em: 22 out. 2005.

DICKEL,E.L.; SANTOS, L. R.; RODRIGUES,L. B.; VALLE, S. F.; CECATTI, D. Ocorrência de Salmonella em abatedouros de aves com tecnologia totalmente automatizada (grande porte), semi automatizada (médio porte) e semi automatizada (pequeno porte). Higiene Alimentar, São Paulo, v.19, n.131, p.62-67, 2005.

EISEL, W. G.; LINTON, R. H.; MURIANA, P. M. A survey of microbial levels for incoming raw beef, environmental souces, and ground beef in a red meat processing plant. Food Microbiology, London, v.14, p.273-282, 1997.

FIRSTENBERG-EDEN, R. S.; NOTERMANS, S.; SCHOTHORST, M. Attachment of certain bacterial strains to chicken and beef meat. Journal of Food Safety, Westport, v.1, p.217-228, 1978.

FRANCO, B. D. G. M.; LANDGRAF, M. Microbiologia dos alimentos. São Paulo: Atheneu, 2002.

GILL, C. O. Microbiological contamination of meat during slaughter and butchering of cattle, sheep and pigs. In: DAVIES, A.; BOARD, R. The Microbiology of Meat and Poultry. London: Blackie Academic and Professional, 1998. p.118-157.

GILL, C. O.; McGINNIS, J. C.; BADONI, M. Use of total or Escherichia coli counts to assess the hygienic characteristics of a beef carcass dressing process. International Journal of Food Microbiology, Amsterdam, v.31, n.1-3, p.181-196, 1996.

HOFER, E.; SILVA FILHO, J. S.; REIS, E. M. F. Serovares de Salmonella isolados de matérias-primas e de ração para aves no Brasil. Pesquisa Veterinária Brasileira, Rio de Janeiro, v.17, p.55-62, 1997.

HOUSTON, D. L. The overview of US department of agriculture requirements. Poultry Science, Champaign, v.64, n.3, p.481-484, 1985.

JAMES, W. O.; PRUCHA, J. C.; BREWER, R. L. CostEfective techniques to control human enteropathogens on fresh poultry. Poultry Science, Champaign, v.72, p.11741176, 1993.

JAY, J. M. Indicators of food microbiological quality and safety. In: _____. Modern food microbiology. 6.ed. Maryland: Aspen Publication, 2000. p.387-407.

LILLARD, H. S. The impact of commercial processing procedures on the bacterial contamination and crosscontamination of broiler carcasses. Journal Food Protection, Des Moines, v.53, n.3, p.202-204, mar. 1990. 
McMEEKIN, T.; THOMAS, C. J. Retention of bacteria on chicken skin after immersion in bacterial suspensions. Journal Applied Bacteriology, Oxford, v.45, n.3, p.383387, 1978.

MEAD, G. C. Bacteriological control in the processing of poultry. Veterinary Record, London, v.95, n.25, p.569-572, 1974.

NOGUEIRA, P. J. P. A.; FRANCO, B. D. G. M. Avaliação de diferentes meios de enriquecimento seletivo e plaqueamento na pesquisa de Salmonella spp. em carcaças de frango. In: CONGRESSO BRASILEIRO DE CIÊNCIAS E TECNOLOGIA DE ALIMENTOS, 15., 1996, Poços de Caldas. Anais... Poços de Caldas: SBCTA, 1996. p.69.

RAMALHO, L. S.; LIMA, S. M.; SILVA, M. C. D. Avaliação de diferentes meios de isolamento na pesquisa de Salmonella spp. em carcaças de frango comercializadas em Maceió. In: CONGRESSO BRASILEIRO DE CIÊNCIA E TECNOLOGIA DE ALIMENTOS, 17., 2000, Fortaleza. Anais... Fortaleza: Sociedade Brasileira de Ciência e Tecnologia de Alimentos, 2000. p.4-144.

REIBER, M. A.; HIERHOLZER, R. E.; ADAMS, M. H.; COLBERG, M.; IZAT, A. L. Effect of litter condition on microbiological quality of freshly killed and processed broilers. Poultry Science, Champaign, v.69, n.12, p.21282133, 1990.

RIPABELL, G.; SAMMARCO, M. L.; RUBERTO, A.; LANNITTO, G.; GRASSO, G. M. Immunomagnetic separation and conventional culture procedure for detection of naturally occurring Salmonella in raw pork sausages and chicken meat. Letters in Applied Microbiology, Oxford, v.24, p.493-497, 1997.

RITTER, R.; BERGMAN, G. P. Eficácia do sistema de préresfriamento em carcaças de frangos. Higiene Alimentar, São Paulo, v.17, n.108, p.97-105, 2003.

SILVA, J. A. Microrganismos patogênicos em carne de frangos. Higiene Alimentar, São Paulo, v.12, n.58, p.9-14, 1998.
SMITH, D. P.; CASON, J. A.; BERRANG, M. E. Effect of fecal contamination and cross-contamination on numbers of coliform, Escherichia coli, Campylobacter and Salmonella on immersion-chilled broiler carcasses. Journal of Food Protection, Des Moines, v.68, n.7, p.1340-1345, 2005.

SOARES, M. M. S. R.; REZENDE, A. C. B.; SREBERNICH, S. M. Análise microbiológica da água utilizada em diversas etapas do abate de aves. In: CONGRESSO BRASILEIRO DE MICROBIOLOGIA, 23., 2005, Santos. Anais... Santos: CBM, 2005. CDROM.

SURKIEWICZ, B. F.; JOHNSTON, R. W.; MORAN, A. B.; KRUMM, G. W. A bacteriological survey of chicken eviscerating plants. Food Technology, Chicago, v.23, n.8, p.1066-1069, 1969.

TALAMINI, D. J. D.; MARTINS, F. M.; NOVAES, M. Embrapa: produção de mercado nacional e internacional do frango. Avicultura Industrial, Porto Feliz, v.97, n.1140, p.20-25, 2005.

THOMAS, C. J.; McMEEKIN, A. T.; PATTERSON, J. T. Prevention of microbial contamination in the poultry processing plant. In: INTERNATIONAL SYMPOSIUM. PREVENTION OF CONTAMINATION AND DESCONTAMINATION IN THE MEAT INDUSTRY, n., 1986, Zeist. Proceedings... Zeist: Elsevier Science, 1986. p.163-179,

THOMSON, J. E.; COX, N. A.; WHITEHEAD, W. K.; MERCURI, A. J.; JUVEN, B. J. Bacterial counts and weight changes of broiler carcasses chilled commercially by water immersion and air-blast. Poultry Science, Champaign, v.54, n.5, p.1452-1460, 1975.

THOMSON, J. E.; COX, N. A.; BAILEY, J. S. Cholrine, acid and heat treatments to eliminate Salmonella on broiler carcasses. Poultry Science, Champaign, v.55, n.4, p.15131517, 1976.

UNIÃO BRASILEIRA DE AVICULTURA. Relatório Anual 2005/2006. Disponível em: <www.uba.org.br>. Acesso em: 26 maio 2007. 
